\title{
ArcheoSciences
}

Revue d'archéométrie

33 (suppl.) | 2009

Mémoire du sol, espace des hommes

\section{Comparison of three arrays in time-lapse ERT: Simulation of a leachate injection experiment}

\author{
R. Clément, M. Descloîtres, T. Gunther and L. Oxarango
}

\section{(2) OpenEdition}

Electronic version

URL: https://journals.openedition.org/archeosciences/1692

DOI: 10.4000/archeosciences. 1692

ISBN: 978-2-7535-1599-4

ISSN: 2104-3728

Publisher

Presses universitaires de Rennes

Printed version

Date of publication: 30 October 2009

Number of pages: $275-278$

ISBN: 978-2-7535-0943-6

ISSN: $1960-1360$

\section{Electronic reference}

R. Clément, M. Descloîtres, T. Gunther and L. Oxarango, "Comparison of three arrays in time-lapse ERT: Simulation of a leachate injection experiment", ArcheoSciences [Online], 33 (suppl.) | 2009, Online since 30 October 2011, connection on 21 September 2021. URL: http://journals.openedition.org/ archeosciences/1692 ; DOI: https://doi.org/10.4000/archeosciences.1692 


\title{
Comparison of three arrays in time-lapse ERT: Simulation of a leachate injection experiment
}

\author{
R. Clément *, M. Descloîtres*, T. Gunther ** and L. Oxarango*
}

Key words: Array-type, Electrical, Tomography, Artefact, Leachate.

Leachate recirculation in bioreactor needs a careful optimization of water content and thus, the knowledge of the leachate plume geometry. Time-lapse Electrical Resistivity Tomography (ERT) is widely use for this purpose. However, in some situations, artefacts of ERT imaging can occur with classical inversion parameters. Using numerical modelling (simulating a 2D infiltration experiment) and standard inversion parameters, this study shows that artefacts may occur using common symmetrical electrode arrays (WennerSchlumberger and dipole-dipole). We show that using asymmetrical array (pole-dipole with forward and reverse data sets), artefacts are significantly reduced to get a more reliable ERT image of leachate infiltration geometry.

\section{INTRODUCTION}

Leachate recirculation in bioreactor allow us to optimise the biodegradation of the waste because the moisture has a major influence on the biodegradation efficiency (Reinhart et al., 2002). In order to delineate water injection inside the waste, ERT is used in time lapse mode thanks to its sensitivity to water content variation (Descloitres et al., 2008). This method is usually considered as robust method, but several authors pointed out that artefact may exist during infiltration phenomena when using standard time-lapse inversion parameters. (Descloitres et al., 2003; Guerin et al., 2004). In this study we show that in some cases apparent resistivity pseudo-sections display apparent resistivity increases at depth. Once inverted, they can be mis-interpreted to become false increases of calculated resistivity. In this paper, we examine to what extent the use of three classical arrays generate or not artefacts of increase of calculated resistivity during a $2 \mathrm{D}$ time-lapse experiment (infiltration trench). This study is based on synthetic modelling using three classical arrays, i.e. Wenner-Schlumberger, dipole-dipole and pole-dipole, and their combination, to show how they generate artefact or not.

\section{Material AND METHOD}

Our study was done in three steps. The first step is the synthetic model building. We used 2D geometry simulating a shallow horizontal injection trench frequently used in bioreactor context (Haydar and Khire, 2005). The model is build from existing data (Moreau et al., 2003; Rosqvist and Dahlin, 2005). We defined two layers. (Fig. 1-A). The first layer is the soil cover (1 metre, sandy-clayey). Its resistivity varies from $90 \Omega . m$ (initial state) to $25 \Omega$.m after injection inside infiltration trench only $(-70 \%)$. The second layer (thickness $15 \mathrm{~m}$ ) corresponds to the waste. Its resistivity varies from $15 \Omega . \mathrm{m}$ to $6 \Omega$.m after injection inside the infiltration affected area (-60\%). The infiltration bulb

* Laboratoire d'étude des Transferts en Hydrologie et Environnement (LTHE), UMR 5564, BP53 38041 Grenoble cedex 9, France.

** Leibniz Institute for Applied Geophysics, Stilleweg 2, D-30655 Hannover Postfach 510153, D-30631 Hannover, Germany. 
shows a width of 8 meter. It penetrates down to 4 meters (Fig. 1-B).

The second step is the calculation of apparent resistivity using the DC2DInvRes software (Günther, 2006). We used 72 electrodes with a unit electrodes spacing of 1 meter using the following arrays:

- Wenner-Schlumberger and dipole-dipole which are symmetrical arrays commonly used for their good vertical and horizontal sensitivity (Loke, 2004).

- Pole-dipole which is asymmetrical array, was used combining forward and reverse data set as proposed by Grellier et al. (2008).

Apparent resistivity pseudo sections are then "noisified" with 3\% Gaussian noise and show:

- Wenner-Schlumberger: decrease of resistivity at the center $(-54 \%)$ and an increase both side the infiltration $(+18 \%)$ (Fig. 2).

- Dipole-dipole : decrease of resistivity at the center $(-62 \%)$ and an increase both side the infiltration $(+36 \%)$ below this decrease (Fig. 2)
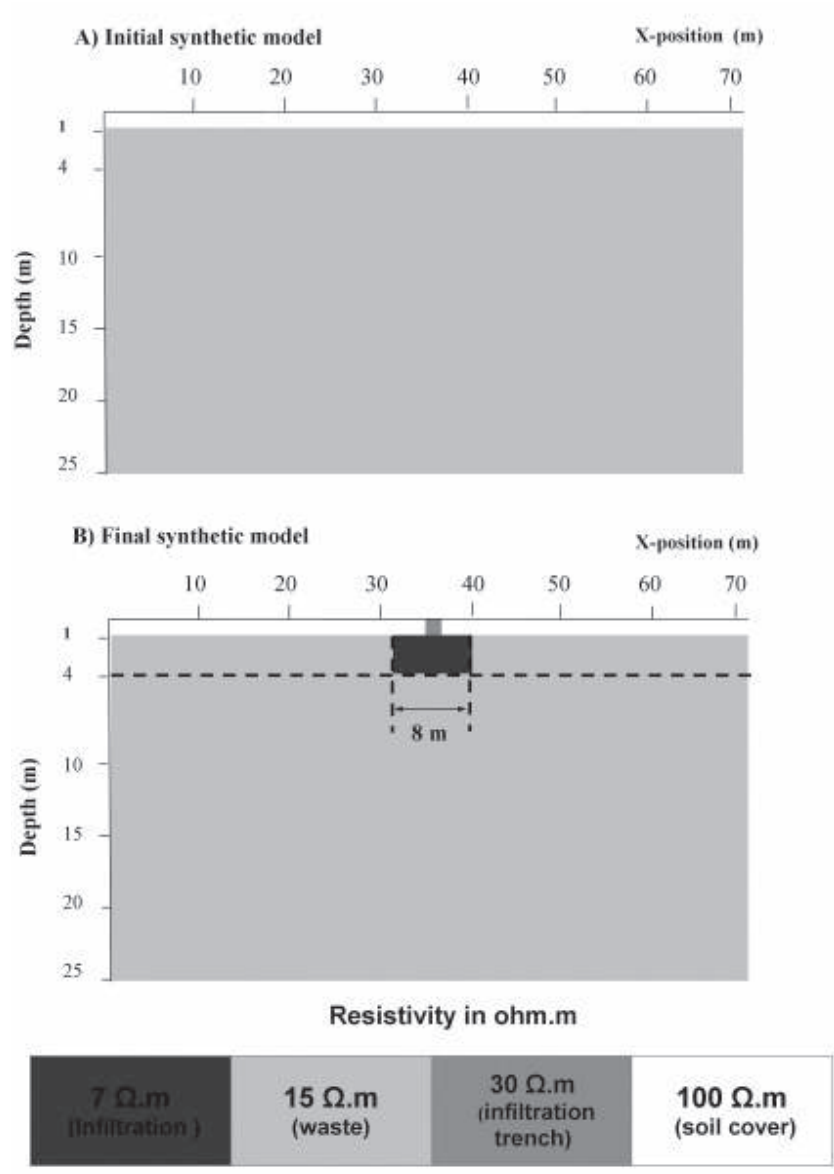

Figure 1: Synthetic model of resistivity for an injection of lixiviat in waste landfill.

\section{Apparent resistivity variation}

(ratio between final and initial models)
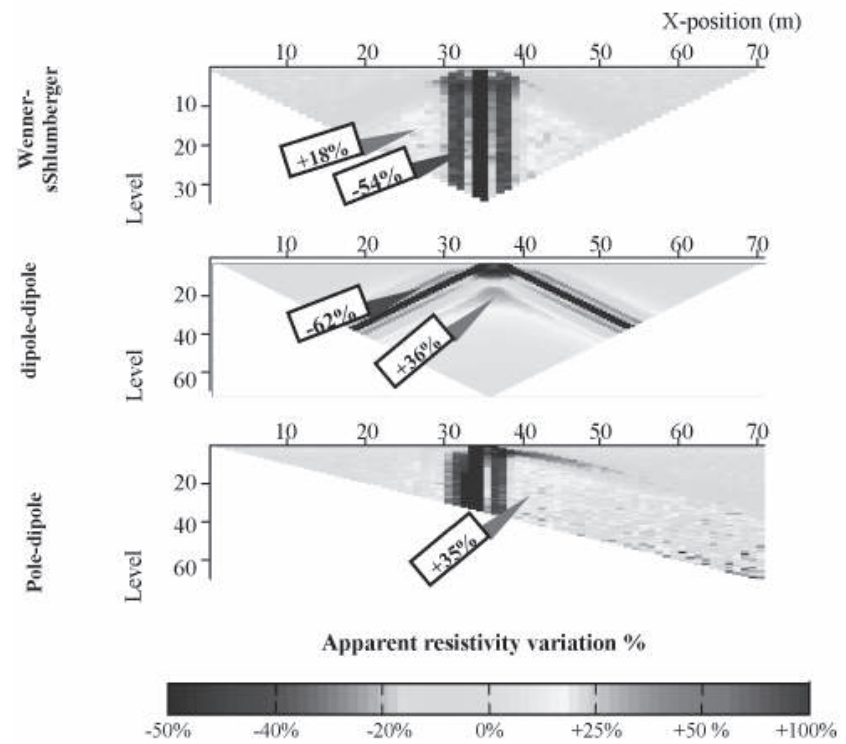

Figure 2 (see color plate): Apparent resistivity variation obtained with three arrays obtenues (Wenner-Schlumberger, dipole-dipole and pole-dipole). The resistivity variations are expressed by $\Delta \rho=((\rho \mathrm{f} / \rho \mathrm{i})$ $\left.1)^{*} 100\right) . \Delta \rho$ is th eresistivity variation, $\rho \mathrm{i}$ is initial resistivity, $\mathrm{pf}$ final resistivity

- Pole-dipole: decrease of resistivity at the center (-60\%) and an increase both side the infiltration $(+35)$ at the right of the profile.

For the third step, we used DC2DInvREs to inverse the synthetic data set. We used a classical set of parameters (Gauss-Newton regularisation, $\lambda=30$, z-weight $=1$, « blocky " option). For time lapse inversion, we used the first calculated model obtained for the first data set as reference model (starting solution) for the second data set inversion, as proposed by Loke (Loke, 2004).

\section{RESUlTS AND DISCUSSION}

The result for time-lapse inversion of Wenner-Schlumberger arrays shows a significant decrease of calculated resistivity down to 10 meters depth. Some artefacts of increase of resistivities $(+25 \%)$ are present both side of the infiltration (Fig. 3-a). Although a Wenner-Schlumberger array is renowned for its good sensitivity to horizontal variations of resistivity, we observed here a poor reconstruction of the model below the bulb. For dipole-dipole array the calculated resistivity variation show a decrease of $-50 \%$ down 5 meters deep. 
Both side of the infiltration we evidenced two artefacts of calculated resistivity increase of $+20 \%$ (Fig. 3-b). In geophysical literature, the combination of Wenner-Schlumberger and dipole-dipole arrays give usually satisfactory results (de la Vega et al., 2003; Seaton and Burbey, 2002). In our case, artefacts of increase of calculated resistivity remained (above $+20 \%)$ and are even more extended (Fig. 3-c).

Combined inversion of forward and reverse pole-dipole data sets show resistivity variation at the center that is in accordance with the synthetic model (a decrease of $-60 \%$ ). Around the infiltration there is a significant improvement in artefact removal: increase of calculated resistivity remains clearly below $+10 \%$. Away from infiltration zone weak variation of resistivity remained but are not exceeding $+/-5 \%$ (Fig. 3-d).

\section{ConCLusion}

During ERT monitoring of leachate infiltration experiment, standard inversion of time lapse resistivity data obtained with symmetrical arrays may produce strong artefacts showing false increases of calculated resistivity.

The use of an asymmetrical array such as pole-dipole (forward and reverse) allows us to reduce significantly artefact of increase of resistivity. Even if this array is more restricting (i.e., one infinite electrode, double acquisition time), we advocate for its use whenever possible in order to get more reliable results if leachate injection, or other infiltration experiments, are under scope with time-lapse ERT.

\section{References}

de la Vega, M., Osella, A. and Lascano, E., 2003. Joint inversion of Wenner and dipole-dipole data to study a gasolinecontaminated soil. Journal of Applied Geophysics, 54(1-2): 97-109.

Descloîtres, M., Ribolzi, O. and Le Troquer, Y., 2003. Study of infiltration in a Sahelian gully erosion area using time-lapse resistivity mapping. Catena, 53(3): 229-253.

Descloîtres, M. et al., 2008. Characterization of seasonal local recharge using electrical resistivity tomography and magnetic resonance sounding. Hydrological Processes, 22(3): 384-394.

Grellier, S. et al., 2008. Monitoring of Leachate Recirculation in a Bioreactor Landfill by 2-D Electrical Resistivity Imaging. Journal of Environmental and Engineering Geophysics, 13(4): 351-359.

\section{Calculated resistivity variations}

a)

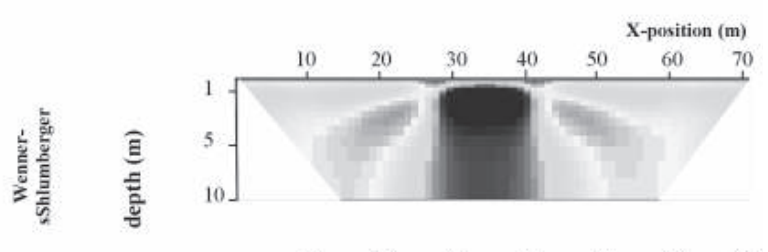

b)

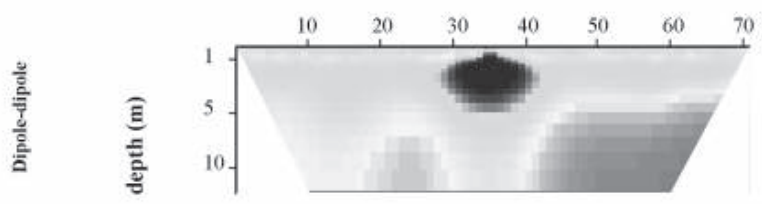

c)

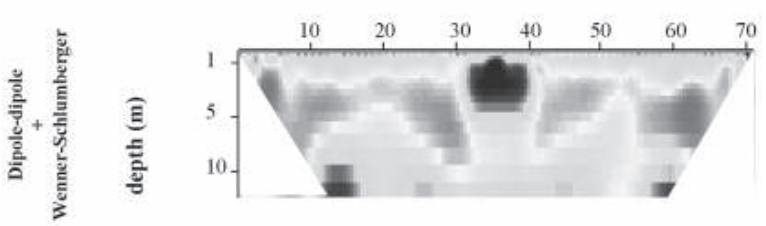

d)

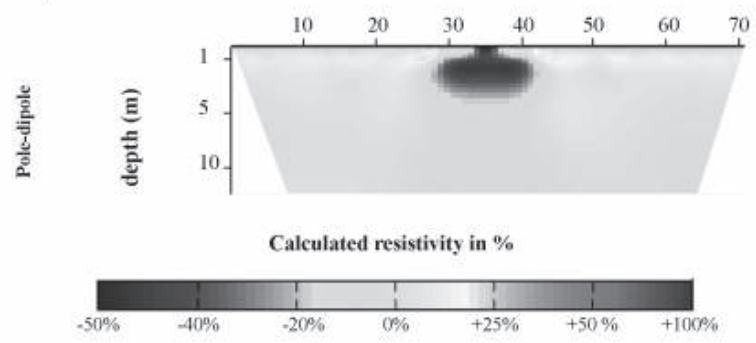

Figure 3 (see color plate): calculated resistivity variation.

GUERIN, R. et al., 2004. Leachate recirculation: moisture content assessment by means of a geophysical technique. Waste Management, 24(8): 785-794.

HaYdar, M. M. and KHIRE, M. V., 2005. Leachate recirculation using horizontal trenches in bioreactor landfills. Journal of Geotechnical and Geoenvironmental Engineering, 131(7): 837-847.

LoKe, M. H., 2004. Tutorial : 2-D and 3-D electrical imaging surveys.

Moreau, S., Bouye, J. M., Barina, G. and Oberty, O., 2003. Electrical resistivity survey to investigate the influence of leachate recirculation in a MSW landfill. In: E. S. E. Centre (Editor), Nineth International Waste Management and landfill Symposium, Calgliari, italy.

Reinhart, D. R., McCreanor, P. T. and Townsend, T., 2002. The bioreactor landfill: Its status and future. Waste Management \& Research, 20(2): 172-186. 
Rosqvist, H. and DAHLIN, T., LenhÉ, C., 2005. Investigation of water flow in a bioractor landfill using geoelectrical imaging techniques. In E. S. E. Centre (Editor), tenth International Waste Management and landfill Symposium, Calgliari, italy.
Seaton, W. J. and BurbeY, T. J., 2002. Evaluation of two-dimensional resistivity methods in a fractured crystalline-rock terrane. Journal of Applied Geophysics, 51(1): PII S09269851(02)00212-4. 